\title{
Effects of Gibberellic Acid, Methyl Jasmonate and Chitosan on Antioxidant Enzyme Activity in Peppermint (Mentha piperita L.)
}

\author{
Farid Soleymani ${ }^{1}$, Henghameh Taheri ${ }^{2}$
}

\begin{abstract}
Peppermint is the major source of menthol rich essential oil and widely cultivated for pharmaceutical purposes. In this study, the effect of exogenous applications of gibberellic acid (GA3), Methyl jasmonate (MeJA) and chitosan (CHT) were investigated on the antioxidant enzymes activities including ascorbate peroxidase (APX) and guaiacol peroxidase (GPX). During timecourse CHT elicitation, APX activity decreased at 12 and $24 \mathrm{~h}$ relative to control while GPX activity significantly increased at $24 \mathrm{~h}$. It seems that CHT treatment can interfere in APX scavenging activity. APX and GPX activity dramatically increased at $24 \mathrm{~h}$ following MeJA treatment compared to untreated plants. Conversely, APX activity remarkably decreased at $24 \mathrm{~h}$ after GA3 treatment compared to control, While GPX activity prominently increased at $24 \mathrm{~h}$ after treatment relative to control. This finding indicated that in comparison to APX, GPX under GA3 and CHT treatments has a greater ROS-scavenging capacity.
\end{abstract}

Keywords - Mentha $\mathrm{x}$ piperita, Menthol, Gibberellic acid, Methyl jasmonate and chitosan.

\section{INTRODUCTION}

$\mathrm{P}$ EPPERMINT is considered as an experimental model system since the past several decades because of its highly enriched sources of essential oils especially monoterpenes. Menthol is C10 isoprenoid which is recognized as the most prominent monoterpenes constituent in peppermint [1]. This valuable natural product has considerable economic importance due to its multitude aromatherapy and industrial applications [2]. It is worth noting that many pharmaceutical metabolites produce when plants subjected to stresses, including various elicitors or signal molecules like hormones $[3,4]$.

Gibberellins are recognized compounds that play an important role in the eliciting the biosynthesis of secondary metabolites in plant cells. Alternatively, the exposure of plants to stresses, including various elicitors or signal molecules such as chitosan, yeast extract and plant hormones like jasmonate and methyl jasmonate is an effective strategy for enhancing the yield of pharmaceutical metabolites [5].

\footnotetext{
${ }^{1}$ Student, Department of Agronomy and Plant Breeding, Ramin Agriculture \& Natural Resources University of Khouzestan, Iran. E-mail: faridsoleymani2012@gmail.com

${ }^{2}$ Assistant Professor, Department of Agronomy and Plant Breeding, Ramin Agriculture \& Natural Resources University of Khouzestan, Iran. Tel: 00986133222424, Fax: 00986133222425, E-mail: hetaheri@alumni.ut.ac.ir
}

Chitosan $((-)(1,4)$-Glucosamine polymer) is produced by the deacetylation of chitin and is localized in the cell wall of pathogenic microorganisms [6]. It is reported that chitosan could be effectively employed as an ideally natural antioxidant by scavenging superoxide anion and hydroxyl radical $[7,8]$.

Methyl jasmonate (MeJA) is derived from linolenic acid by the octadecanoid pathway and induce in response to pathogen attack or wounds that leads to accumulation of reactive oxygen species (ROS) in plant cells [9]. These compounds are then scavenged by many enzymes such as ascorbate peroxidase (APX) and guaicol peroxidase (GPX) to alleviate their adverse effects [10]. Peroxidases which are single-chain polypeptides, catalyze the reduction of hydrogen peroxidase $\left(\mathrm{H}_{2} \mathrm{O}_{2}\right)$ to water. On the basis of their function and sub-cellular localization are classified into two different categories. Those peroxidase utilizing guaicol as electron donor, are called guaicol peroxidase (GPX) and those that utilize ascorbate as electron doner are ascorbate peroxidase (APX). Unlike APXs that are localized in cytosol and chloroplast, GPXs are not found in organelle and are located in cytosol, cell wall and in extracellular space compartment [11].

In this study we investigated the effect of time - course exogenous application of $\mathrm{GA}_{3}$, MeJA and chitosan (CHT) on M. piperitato evaluate the ability of ROS scavenging, total protein content and protective effects of the antioxidant enzyme system in M. piperita by changing APX and GPX activities under aforementioned treatments. The present study will help to figure out whether $\mathrm{GA}_{3}, \mathrm{MeJA}$ and chitosan (CHT) affect antioxidant enzyme activities.

\section{MATERIALS AND METHODS}

\subsection{Plant Materials, GA3, MJ and chitosan Treatment and Samplings}

This experiment was carried out under natural light conditions in the greenhouse of, Ramin Agriculture and Natural Resources University of Khouzestan (IRAN). The rhizomes of peppermints were collected from Pakanbazr Company, Esfahan, Iran. Then $10-15 \mathrm{~cm}$ rhizomes were transferred into pots. They were watered every day. Two months-old uniform plants were selected for sampling.

GA3, MeJA and CHT were purchased from Sigma Aldrig Company. In order to treat the plants $50 \mathrm{mg} / \mathrm{L} \mathrm{GA} 3$ in distilled water, $0.3 \mathrm{mM}$ MeJA in $2 \%$ (v/v) ethanol and $200 \mathrm{mg} / \mathrm{L}$, CHT 
in $2 \%(\mathrm{v} / \mathrm{v})$ Acetic acid was sprayed on the surface of the peppermint plants. The untreated peppermint plants (control) were sprayed with only distilled water, $2 \%(\mathrm{v} / \mathrm{v})$ ethanol and $2 \%(\mathrm{v} / \mathrm{v})$ Acetic acid respectively. Leaves from the untreated (control) and treated peppermint plants were randomly sampled at 12, 24 and $72 \mathrm{~h}$ after treatment. For each sampling, 4 leaves under the second visible leaf from the apex were harvested, frozen in liquid nitrogen and stored at $-80{ }^{\circ} \mathrm{C}$.

\subsection{Antioxidant Enzyme Activity and Total Protein}

In order to determination of protein, $0.2 \mathrm{gr}$ of leaf tissue was ground and homogenized in $2 \mathrm{ml}$ of potassium phosphate buffer $100 \mathrm{mM}(\mathrm{pH}=7)$ in a pestle mortar and centrifuged at 13,000 RPM for $15 \mathrm{~min}$. The supernatant was used to measure the antioxidant enzymes and total protein solution. All these steps were performed at $4{ }^{\circ} \mathrm{C}$. Total proteins were estimated by the method of Biuret using the total protein kit (Pars Azmoon, Tehran, Iran) with BSA protein as a standard control and following equation was extracted.

1. $Y=0.014 X+0.0108$

$\mathrm{Y}$ : absorption amount, $\mathrm{X}$ : total protein $(\mathrm{mg} / \mathrm{ml})$.

The amount of total protein ( $\mathrm{g} / \mathrm{kg}$ dry weight) was estimated by using the following equation:

\section{2: $C=X \times(V / M)$}

$\mathrm{V}$ : volume of the extract (ml), M: sample weight used for the extraction $(\mathrm{g})$.

Peroxidase enzyme activity assay was carried out based on Chance and Maehly method [12]. Guaiacol oxidation was measured as an increase absorbance at $470 \mathrm{~nm}$ during a minute. Ascorbate peroxidase enzyme activity was assayed by reduction in optical density due to ascorbic acid absorbance at $290 \mathrm{~nm}$ during a minute [13]. The specific activity of both antioxidant enzymes was performed using the following equation.

3: $Z=V * X$

4: $A=(1000 * O D$ difference $) / Z$

$Z$ : the standard value used to calculate the specific activity of enzymes.

$\mathrm{V}$ : volume of the extract used (Microliter).

$\mathrm{X}$ : total protein $(\mathrm{mg} / \mathrm{ml})$.

A: specific activity of the enzyme (OD / $\mathrm{min} / \mathrm{mg}$ protein)

\subsection{Statistical Analyzes}

Two randomly selected plants of each treatment were used for measuring antioxidant enzyme activity and total protein. Results were compared with a T-test $(\mathrm{p}<0.05)$.

\section{RESULTS}

\subsection{GPX and APX Enzyme Activity and Total Protein}

We measured the activities of antioxidant enzymes to investigate the effect of exogenous application of CHT, MeJA and $\mathrm{GA}_{3}$ on ROS-scavenging system. During time-course CHT elicitation, APX activity remarkably decreased at 12 and $24 \mathrm{~h}$ relative to control while GPX activity significantly increased at
$24 \mathrm{~h}$ (Figure 1). This finding is conflicting with former studies which demonstrated that CHT treatment induced a significant increase in the activity of peroxidase [14, 15].

APX and GPX activity dramatically increased at $24 \mathrm{~h}$ following MeJA treatment compared to untreated plants (Figure 2). This relationship between MeJA treated plants and increased activities of antioxidant enzymes has been demonstrated in barley [16], berries [17], Arabidopsis [18].

After $\mathrm{GA}_{3}$ treatment, APX activity no significantly increased at $12 \mathrm{~h}$ posttreatment compared to control while this activity remarkably decreased at $24 \mathrm{~h}$ relative to control (Figure 3). This finding is supported by previous findings that $\mathrm{GA}_{3}$ can strongly down-regulate the amounts and activities of scavenging enzymes, including ascorbate peroxidase in barley aleurone layer [19]. In contrast, GPX activity prominently increased respectively at 12 and $24 \mathrm{~h}$ after $\mathrm{GA}_{3}$ treatment relative to control (Figure 4). Evidences exist that confirm increase in antioxidant enzyme activities under GA treatment, especially in various stressful conditions [20-22].

Protein content dramatically increased at $12 \mathrm{~h}$ after CHT treatment compared to control (Figure 4). Conversely, no significant changes in total protein content were detectable at 24 and $72 \mathrm{~h}$ posttreatment relative to untreated plants. As well as total protein content were not affected by MeJA treatment. Also no significant changes in total protein content were detectable at 12 and $24 \mathrm{~h}$ after $\mathrm{GA}_{3}$ treatment relative to untreated plants. In contrast, protein content dramatically increased at $72 \mathrm{~h}$ posttreatment compared to control (Figure 4).Recent study has reported the same effect of $\mathrm{GA}_{3}$ on enhancement of total protein content [23].

\section{DISCUSSION}

To minimize the damaging results of ROS, plants use a lot of evolved non- and enzymatic antioxidant systems. Enzymatic antioxidant systems provide protection against the toxic effects of ROS. Among the antioxidant enzymes, APX and GPX have a higher affinity for $\mathrm{H}_{2} \mathrm{O}_{2}$ [24]. Ascorbate, on the other hand, acts as a substrate for GA biosynthesis [25]. Several lines of evidences confirm that there are interactions between ascorbate and GA biosynthesis [26, 27]. In recent experiment, reduced ability to metabolize ROS in GA- treated cell is likely related to an accumulation of hydrogen peroxide and ultimately programmed cell death. Since APX and GPX have an identical affinity toward $\mathrm{H}_{2} \mathrm{O}_{2}$, thus hydrogen proxide accumulation and cell death in GA-treatment cannot justify reduced APX activity. Ascorbate, on the other hand, acts as a substrate in GA biosynthesis, therefore reduction in APX activity is likely related to interactions between the pathway of ascorbate and gibberellin signaling. Nevertheless this relationship has not been fully elucidated yet.

According to recognized antioxidant properties of CHT and declined APX activity during CHT treatment, there is the interesting question arising from these findings. It seems that CHT treatment can interfere in APX scavenging activity. Further studies are required to shed more light on the exact relationship between these compartments.

As mentioned above, JA regulates scavenger enzyme activities in response to environmental stimuli through the 
activation of plant defense mechanism. It seems that MeJA could affect the antioxidant enzyme activities resulted in an increase in $\mathrm{H}_{2} \mathrm{O}_{2}$ generation [28].

\section{CONCLUSION}

The finding of this study indicated that an increase in antioxidant enzyme activity and the resulting increase in ROSscavenging capacity of MeJA - treated plants. APX and GPX showed the largest increase in activity, peaking on $24 \mathrm{~h}$ of the MeJA treatment. GPX activity also increased peaking on $24 \mathrm{~h}$ of CHT and GA3 treatment. Conversely, the activity of APX decreased on $24 \mathrm{~h}$ of CHT and GA3. This finding indicated that in comparison to APX, GPX under GA3 and CHT treatments has a greater ROS-scavenging capacity

\section{ACKNOWLEDGMENTS}

The experiment was performed in the central laboratory of Ramin University, Khouzestan, Iran. The authors are thankful to the laboratory personals for putting all the means at our disposal.

\section{REFERENCES}

[1] K. Bauer., R. Conrad and W. Seiler, "Co production hoherer pflanzen in naturlichen standorten," Pflanzenphysiol, vol. 94, pp. 219-230, 1979. http://dx.doi.org/10.1016/S0044-328X(79)80161-0

[2] B.M. Lange. And A. Ahkami, "Metabolic engineering of plant monoterpenes, sesquiterpenes and diterpenes - current status and future opportunities," Plant Biotechnol, vol. 11, pp, 169-196, 2013.

[3] J. Zhao, L. C. Davi. and R. Verpoorte, "Elicitor signal transduction leading to production of plant secondary metabolites," Biotechnol Adv, vol. 23, pp. 283-333, 2005. http://dx.doi.org/10.1016/j.biotechadv.2005.01.003

[4] A. Ramakrishna. and G. A. Ravishankar, "Influence of abiotic stress signals on secondary metabolites in plants," Plant Signal Behav, vol. 6, pp. 1720-31, 2011 http://dx.doi.org/10.4161/psb.6.11.17613

[5] R. A. Dixon. and N. L. Paiva, "Stress-Induced Phenylpropanoid Metabolism," Plant Cell, vol. 7, pp. 1085-1097, 1995. http://dx.doi.org/10.1105/tpc.7.7.1085

[6] GK. Agrawal., R. Rakwal., S. Tamogami., M. Yonekura., A. Kubo. and H. Saji, "Chitosan activates defense/stress response(s) in the leaves of Oryza sativa seedlings" Plant Physiol. Biochem, vol. 40, pp. 10611069, 2002. http://dx.doi.org/10.1016/S0981-9428(02)01471-7

[7] P. J. Park., J. U. Je, and S. K. Kim, "free radical scavenging of chitooliosaccharides y electron spin resonance spectrometry," Journal of Agricultural and Food Chemistry, vol. 51, pp. 4624-4627, 2003. http://dx.doi.org/10.1021/jf034039+

[8] M. Garcia., Y. Silva, and A. Casariego, "Development of a mayonnaise with chitosan as natural antioxidant," Emirates Journal of Food \& Agriculture, vol.26: p835, 2014.

[9] A. Devoto, and J. G. Turner, " Regulation of Jasmonate-mediated plant responses," Annals of Botany, vol. 92, pp. 329-337, 2003. http://dx.doi.org/10.1093/aob/mcg151

[10] F. Van Breusegem., E. Vranova., J. F. Dat. and D. Inze, "The role of active oxygen species in plant signal transduction," Plant Sci, vol. 131, pp. 405-414, 2001. http://dx.doi.org/10.1016/S0168-9452(01)00452-6

[11] K. Asada, "Ascorbate peroxidase - a hydrogen peroxide-scavenging enzyme in plants," Physiologia Plantarum, vol. 85, pp. 235-241, 1992. http://dx.doi.org/10.1111/j.1399-3054.1992.tb04728.x

[12] B. Chance. And A. C. Maehly, "Assay of catalase and peroxidase," Methods in Enzymology, vol. 2, pp. 764-775, 1955. http://dx.doi.org/10.1016/S0076-6879(55)02300-8

[13] C. Jebara., M. Jebara., M., Limam., F. and M. ElarbiAouani, "Changes in ascorbate peroxidase, catalase, guaiacol peroxidase and superoxide dismutase activities in common bean (Phaseolus vulgaris) nodules under salt stress," Plant Physiol, vol. 162, pp. 929-936, 2005. http://dx.doi.org/10.1016/j.jplph.2004.10.005

[14] S. Mandal, "Induction of phenolics, lignin and key defense enzymes in eggplant (Solanum melongena L.) roots in response to elicitors," African Journal of Biotechnology, vol. 9, pp. 8038-8047, 2010.

[15] S. Naderi., B. Fakheri, and S. Esmailzadehbahabadi, "Increasing of Chavicol o- Methyl Transfrase Gene Expression and Catalase and Ascorbate Peroxidase Enzymes Activity of Ocimum basilicum by Chitosan.," Crop Biotech, vol. 6, pp. 1-9, 2014.

[16] L. Popova., E. Ananieva., V. Haristov., K. Christo., K. Georgier., E. Alexiev. and ZH. Stoinova, "Salicylic acid and methyl jasmonateinduced protection onphotosynthesis to paraquat oxidative stress," Bulg. J. Plant Physiol, pp. 133-152, 2003.

[17] K. Chanjirakul., S. Y. Wang., C. Y. Wang. and J. Siriphanich, "Effect of natural volatile compounds on antioxidant capacity and antioxidant enzymes in raspberries," Postharvest Biology and Technology, vol 40, pp. 106-115, 2006. http://dx.doi.org/10.1016/j.postharvbio.2006.01.004

[18] S. Berger, "Jasmonate-related mutants of Arabidopsis as tools for studying stress signaling," Planta, vol. 214, pp. 497-504, 2002. http://dx.doi.org/10.1007/s00425-001-0688-y

[19] A. Fath., P. C. Bethke. and R. L. Jones, "Enzymes That Scavenge Reactive Oxygen Species Are Down-Regulated Prior to Gibberellic Acid-Induced Programmed Cell Death in Barley Aleurone," Plant Physiol, vol. 126, pp. 156-166, 2001. http://dx.doi.org/10.1104/pp.126.1.156

[20] L. Qingzhu., L. Chaohan., Y. Xianchang. and S. Qinghua, "Gibberellin pretreatment increased antioxidative capacity of cucumber radicles and hypocotyls under suboptimal temperature," African journal of agricultural research, vol. 6, pp. 4091-4098, 2011.

[21] S. Saeidi-Sar., H. Abbaspour., H. Afshari. and S. R. Yaghoobi, "Effects of ascorbic acid and gibberellin A3on alleviation of salt stress in common bean (Phaseolus vulgaris L.) seedlings," ActaPhysiologiae Plant, vol. 35, pp. 667-677, 2013. http://dx.doi.org/10.1007/s11738-012-1107-7

[22] O. Younesi. and A. Moradi, (2014) "Effect Of Priming Of Seeds Of Medicago Sativa 'Bami' With Gibberellic Acid On Germination, Seedlings Growth And Antioxidant Enzymes Activity Under Salinity Stress," Journal of Horticultural Research, vol. 22, pp. 167-174, 2014. http://dx.doi.org/10.2478/johr-2014-0034

[23] R. Firuzeh., R. A. Khavari-Nejad., F. Najafi. and S. Saadatmand, (2015) Effect of Gibberellins on Sugar, Protein and Malondialdehyde Contents in Savory Plant (Saturejahortensis L.) under Salt Stress," Journal of Applied Environmental and Biological Sciences. Vol. 5, pp. 23-29, 2015.

[24] R. Mittler and T. L. Poulos, "Ascorbate peroxidase, Antioxidants and reactive oxygen species in plants," Oxford: Blackwell Publishing, pp: 87-100, 2005

[25] A. G. Prescott. and P. John "Dioxygenases: molecular structure and role in plant metabolism," Annual Review of Plant Physiology and Plant Molecular Biology, vol. 47, pp. 245-271, 1996.

http://dx.doi.org/10.1146/annurev.arplant.47.1.245

[26] G. M. Pastori., G. Kiddl., J. Antoni., S. Bernar., S. Veljovic-Jovanovi., P. J. Verrier., G. Noctor. and C. H. Foyer, "Leaf vitamin C contents modulate plant defense transcripts and regulate genes that control development through hormone signaling," The Plant Cell," vol. 15, pp. 939-951, 2003. http://dx.doi.org/10.1105/tpc.010538

[27] P. I. Kerchev., T. K. Pellny., P. D. Vivancos., G. Kiddle., P. Hedden., S. Driscoll., et al, "The transcription factor ABI4 Is required for the ascorbic acid-dependent regulation of growth and regulation of jasmonate-dependent defense signaling pathways in Arabidopsis," Plant Cell, vol. 23, pp. 3319-3334, 2011. http://dx.doi.org/10.1105/tpc. 111.090100

[28] MC. Parra-Lobato., N. Fernandez-Garcia., E. Olmos., MC. AlvarezTinaut. and MC. GomezJimenez, "Methyl jasmonate-induced antioxidant defence in rootapoplast from sunflower seedlings," Environmental and Experimental Botany, vol. 66, pp. 9-17, 2009. http://dx.doi.org/10.1016/j.envexpbot.2009.01.002 


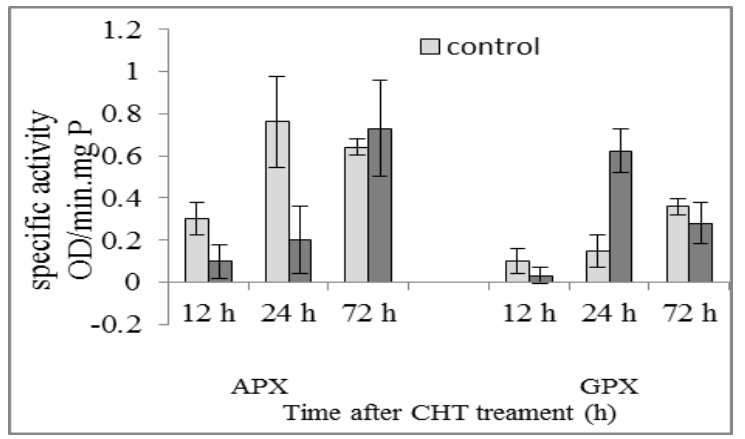

Fig. 1: APX and GPXenzyme activity in leaves at 12, 24 and 72 hours after the CHT treatments.

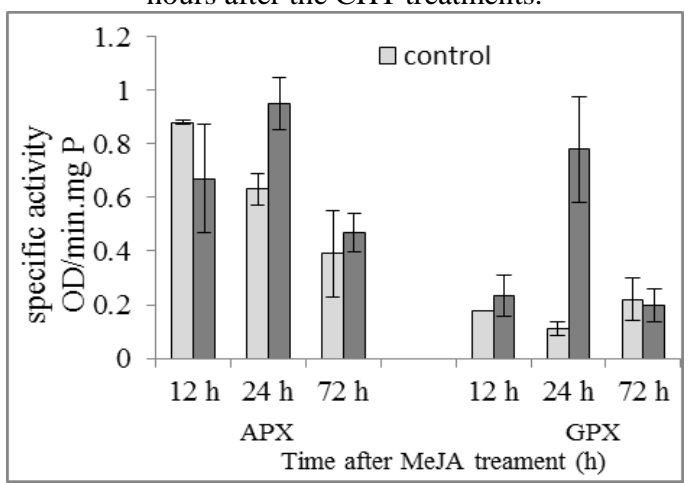

Fig. 2: APX and GPXenzyme activity in leaves at 12, 24 and 72 hours after the MeJA treatments

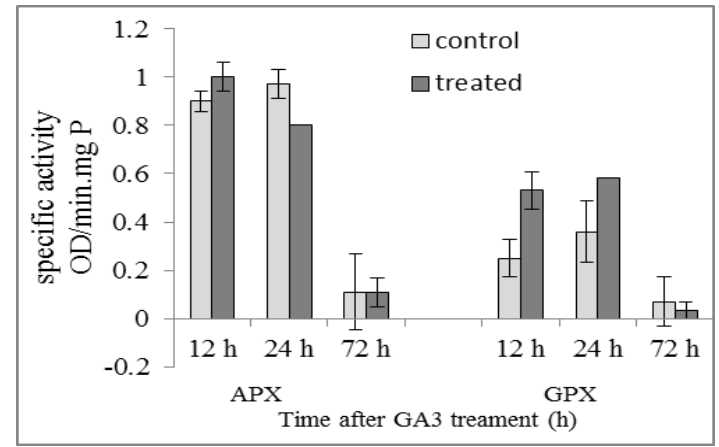

Fig. 3: APX and GPXenzyme activity in leaves at 12, 24 and 72 hours after the $\mathrm{GA}_{3}$ treatments

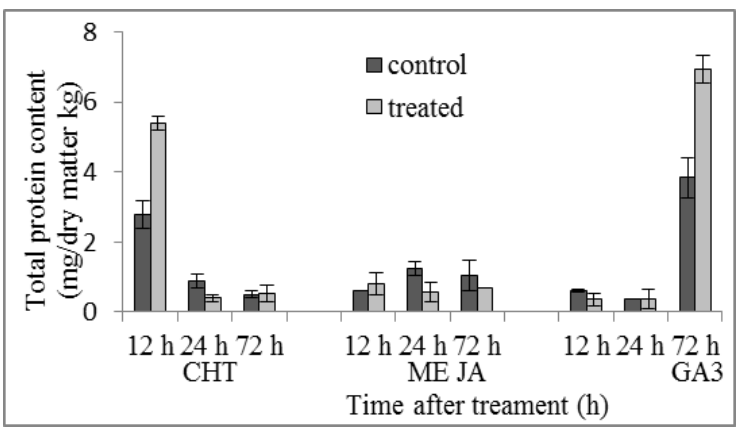

Fig. 4: Total protein content in leaves at 12, 24 and 72 hours after the GA3, CHTand MeJA treatments. 